\title{
Fine Needle Aspiration Cytology of Benign Salivary Gland Tumors with Myoepithelial Cell Participation: An Institutional Experience of 575 Cases
}

\author{
Soomin Ahn Yuil Kim Young Lyun Oh \\ Department of Pathology, Samsung Medical Center, Sungkyunkwan University School of Medicine, Seoul, Korea
}

\section{Key Words}

Pleomorphic adenoma - Basal cell adenoma .

Myoepithelioma · Cytology · Fine needle aspiration

\begin{abstract}
Objective: The aim of this study was to evaluate the diagnostic accuracy of fine needle aspiration (FNA) cytology of benign salivary gland tumors with myoepithelial cell participation, namely, pleomorphic adenoma, basal cell adenoma and myoepithelioma, at a single institution over a period of 10 years. Study Design: This study was based on 575 cytologic and matching histological samples (534 pleomorphic adenomas, 26 basal cell adenomas and 15 myoepitheliomas). Results: In most cases (393/534) of pleomorphic adenoma, a precise diagnosis was given. However, only 2 cases of basal cell adenoma and 1 case of myoepithelioma were diagnosed definitively. Descriptive diagnosis, instead of a definite diagnosis, was rendered in $16.9 \%$ of pleomorphic adenomas, $53.8 \%$ of basal cell adenomas and $40.0 \%$ of myoepitheliomas. Among all cases, the possibility of malignancy was raised in $5.2 \%$ of pleomorphic adenomas, $15.4 \%$ of basal cell adenomas and $20.0 \%$ of myoepitheliomas with a variable degree of suspicion. Conclusion: In some cases, the distinction between these three neoplasms remains difficult in
\end{abstract}

that all exhibit some degree of myoepithelial participation. However, FNA showed a high diagnostic accuracy in diagnosing benign salivary tumors with myoepithelial differentiation, and triage into this category provides sufficient information for clinicians to make treatment decisions.

(c) 2013 S. Karger AG, Basel

\section{Introduction}

Fine needle aspiration (FNA) cytology is an established technique that offers high sensitivity, specificity and diagnostic accuracy in salivary tumor diagnosis [14]. Pleomorphic adenoma is the most common tumor of the salivary glands, comprising about $60 \%$ of all salivary neoplasms [5]. Thus, it is the most commonly encountered tumor in FNA. The reliability of FNA in diagnosing pleomorphic adenoma has been reported to be 89.596.2\%. Therefore, most preoperative diagnoses of pleomorphic adenoma rely on FNA. Despite the high level of diagnostic accuracy in identifying pleomorphic adenoma, they may pose diagnostic challenges for the cytopathologist in some difficult cases. On occasion, pleomorphic adenomas are mistaken for several other types of tumors [6]. In contrast, some tumors cytologically resemble

\section{KARGER}

E-Mail karger@karger.com

www.karger.com/acy (c) 2013 S. Karger AG, Basel

0001-5547/13/0576-0567\$38.00/0
Correspondence to: Prof. Dr. med. Young Lyun Oh Department of Pathology, Samsung Medical Center Sungkyunkwan University School of Medicine 50 Ilwon-dong, Gangnam-gu, Seoul 135-710 (Korea) E-Mail bijou@skku.edu 
pleomorphic adenoma. In particular, myoepithelioma and basal cell adenoma are frequently diagnosed as pleomorphic adenoma [6].

In terms of tumor classification, myoepithelioma and basal cell adenoma are considered to belong to the spectrum of pleomorphic adenoma in that all of these tumors exhibit myoepithelial cell participation [7]. While pleomorphic adenoma can be easily diagnosed from FNA slides, the diagnosis of myoepithelioma and basal cell adenoma remains difficult. This difficulty arises due to their rarity, sampling limitations of FNA and the overlapping characteristics of pleomorphic adenoma. The aim of this study was to evaluate the diagnostic accuracy of FNA cytology of benign salivary tumors with myoepithelial cell participation, namely, pleomorphic adenoma, basal cell adenoma and myoepithelioma, at a single institution over a period of 10 years.

\section{Materials and Methods}

This study is a large retrospective analysis of the diagnostic accuracy of benign salivary tumors with myoepithelial participation, namely, pleomorphic adenoma, myoepithelioma and basal cell adenoma, at Samsung Medical Center, Seoul, South Korea, over a period of 10 years. Aspirates were obtained from 575 patients comprised of 193 males and 382 females. The age range was 12-80 years (mean age 45.6). The samples were derived from the parotid gland (457 cases), the submandibular gland (101 cases) and minor salivary glands (17 cases). Most FNAs (498/575) were performed by pathologists using 23 - or 25-gauge needles attached to a $10-\mathrm{ml}$ syringe holder. US-guided aspiration was performed for the remainder of patients. Some smears were air dried and stained with Diff-Quik (Sysmex Corporation, Kobe, Japan), while the remainder were wet fixed with alcohol and stained with hematoxylin and eosin and Papanicoalou. In most cases, preoperative imaging studies were also performed. A large number of patients (470/575) underwent computed tomography (CT) scanning during work-up.

The 575 cytologic and matching histological samples consisted of 534 pleomorphic adenomas, 26 basal cell adenomas and 15 myoepitheliomas. Cytologic diagnosis was classified into 4 categories: category 1, straightforward diagnosis; category 2, descriptive diagnosis rather than definite diagnosis; category 3 , nondiagnostic benign lesion or other benign lesion; and category 4, malignancy. Category 2 specifically refers to cases which were triaged as benign salivary tumors with myoepithelial cell participation, and differential diagnosis included 1 or 2 of these 3 entities. Category 2 was subdivided into two groups based on whether malignancy was likely or not: one group included descriptive diagnosis without suspicion of malignancy, and the other group descriptive diagnosis with suspicion of malignancy. If the most likely diagnosis was benign but differential diagnosis included a low possibility of malignancy, that case was triaged into the latter group. Category 3 referred to either a nondiagnostic benign lesion or another benign lesion. To be specific, a nondiagnostic benign lesion included a low cellular specimen, a specimen containing only normal salivary gland tissue and a specimen containing only cystic fluid. On the other hand, other benign lesions included chronic sialadenitis, salivary gland tumor of another category and other soft tissue or skin lesions.

The accuracy of the cytologic diagnosis was evaluated for each pleomorphic adenoma, myoepithelioma and basal cell adenoma. Histologic diagnosis was made according to WHO criteria, and some difficult cases were consulted by a head and neck pathology specialist. All FNA as well as histologic samples corresponding to basal cell adenoma and myoepithelioma were reviewed.

\section{Results}

Diagnostic Accuracy of Pleomorphic Adenoma, Myoepithelioma and Basal Cell Adenoma

The results of FNA cytologic diagnoses are summarized in table 1 . In most cases (393/534 cases) of pleomorphic adenoma, a straightforward diagnosis (category 1) was given. In contrast, only 2 cases of basal cell adenoma and 1 case of myoepithelioma were diagnosed definitely. Four cases of myoepithelioma and 2 cases of basal cell adenoma were diagnosed as pleomorphic adenoma.

A descriptive diagnosis, rather than a definite diagnosis (category 2), was rendered in $16.9 \%(90 / 534)$ of pleomorphic adenomas, $53.8 \%(14 / 26)$ of basal cell adenomas and $40.0 \%(6 / 15)$ of myoepitheliomas. In most cases, a differential diagnosis including 1 or 2 of these 3 entities was given. Among category 2, the possibility of malignancy was raised in $4.5 \%(24 / 534)$ of pleomorphic adenomas, $11.5 \%(3 / 26)$ of basal cell adenomas and $6.7 \%(1 / 15)$ of myoepitheliomas with a variable degree of suspicion.

Regarding malignancy, there were 4 false-positive malignancy diagnoses for pleomorphic adenoma, 1 for basal cell adenoma and 2 for myoepithelioma (category 4). The most common diagnostic error was adenoid cystic carcinoma (3/7). The remaining diagnostic errors included myoepithelial carcinoma, carcinoma ex pleomorphic adenoma and low-grade carcinoma. Among all preoperative CT interpretations, malignancy was suggested in a total of 28 cases. Preoperative CT was performed in all 7 false-positive cases. The CT interpretations were as follows: benign tumor such as pleomorphic adenoma $(3 / 7)$, indeterminate nature (3/7) and malignant tumor $(1 / 7)$.

Among category 3, 15 (2.6\%) of 575 cases were diagnosed as 'cystic fluid only' ( 11 for pleomorphic adenoma, 1 for myoepithelioma and 3 for basal cell adenoma). There were also some cases diagnosed as mesenchymal tumors or adnexal lesions. The possibility of a neurogenic tumor including schwannoma was raised in 3 cases of 
Table 1. Result of cytologic diagnosis

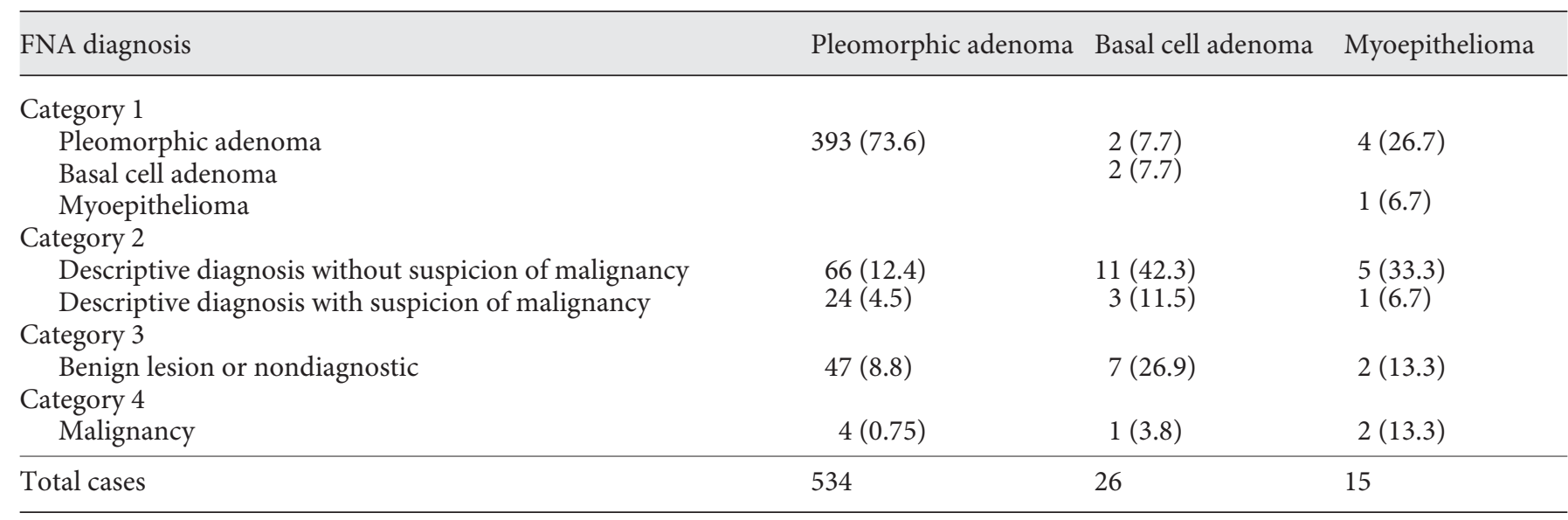

Figures in parentheses are percentages.

pleomorphic adenoma. The possibility of a skin adnexal lesion and fibroblastic tumor was mentioned in 2 cases and 1 case of pleomorphic adenoma, respectively. There were 2 cases of pleomorphic adenoma misdiagnosed as Warthin tumor.

\section{Cytologic Features of Basal Cell Adenoma}

Cytologic slides were available for 17 out of 26 basal cell adenomas and reviewed by 2 pathologists. Among these 17 cases, 3 FNAs were unsatisfactory specimens. Three inadequate specimens consisted of cystic fluid with scant cellularity. The rest of the specimens were histologically analyzed.

Histologically, the tumor subtype was divided as follows: tubular-trabecular (8/14), solid-trabecular (2/14), solid-tubular (2/14), membranous (1/14), and solid $(1 / 14)$. Cytologic features are summarized in table 2. In cytologic slides, tumor cells were arranged in relatively large clusters and rarely as single cells. The borders of clusters were smooth and well defined. Tumor cells consisted of small, uniform and basaloid cells with a cohesive pattern. There was no significant cytologic atypia, mitoses or necrosis in any reviewed cases. Compared to pleomorphic adenoma and myoepithelioma, the tumor cells of basal cell adenoma were small with scant cytoplasm and had hyperchromatic nuclei. However, some tumor cells had oval to spindle shapes in smear specimens, which made it difficult to distinguish them from other spindle cell neoplasms such as pleomorphic adenoma or myoepithelioma. Interestingly, spindle-shaped morphology was identified in 8 out of 14 cases (fig. 1a). In most cases
Table 2. Cytologic features of basal cell adenoma

\begin{tabular}{lc}
\hline Characteristic cytology & Cases \\
\hline Tight cluster & $14 / 14(100)$ \\
Palisading pattern & $5 / 14(35.7)$ \\
Hyaline material & $8 / 14(57.1)$ \\
Two-cell population & $3 / 14(21.4)$ \\
Luminal pattern & $6 / 14(42.9)$ \\
Hyperchromatic cells & $14 / 14(100)$ \\
Spindle cell morphology & $8 / 14(57.1)$ \\
\hline
\end{tabular}

Figures in parentheses are percentages.

exhibiting spindle cell morphology, differential diagnosis included myoepithelioma and pleomorphic adenoma. Among these cases, the possibility of other mesenchymal tumors was added in 2 cases.

Extracellular metachromatic hyaline material, a palisading pattern and tubular structure were commonly seen in basal cell adenoma, which could be helpful for diagnosis. Extracellular hyaline material surrounded the tumor cells in the form of thick bands. Hyaline material surrounding the periphery of tumor cells was observed in 8 out of 14 cases (fig. 1b). A palisading pattern was seen along the periphery of tumor cells in 5 out of 14 cases (fig. 1c). In addition, a tubular configuration was observed in the middle of cellular aggregates in 6 out of 14 cases (fig. 1d). There were no cases of fibromyxoid stroma, which is commonly seen in pleomorphic adenoma. 
Fig. 1. Cytologic features of basal cell adenoma. a In many cases, a spindle-shaped morphology is observed. b Extracellular hyaline material surrounds the tumor cells in the form of thick bands. c Palisading tumor cells are observed along the periphery of the groups. $\mathbf{d}$ The luminal appearance of the tubular structure is seen (arrow).

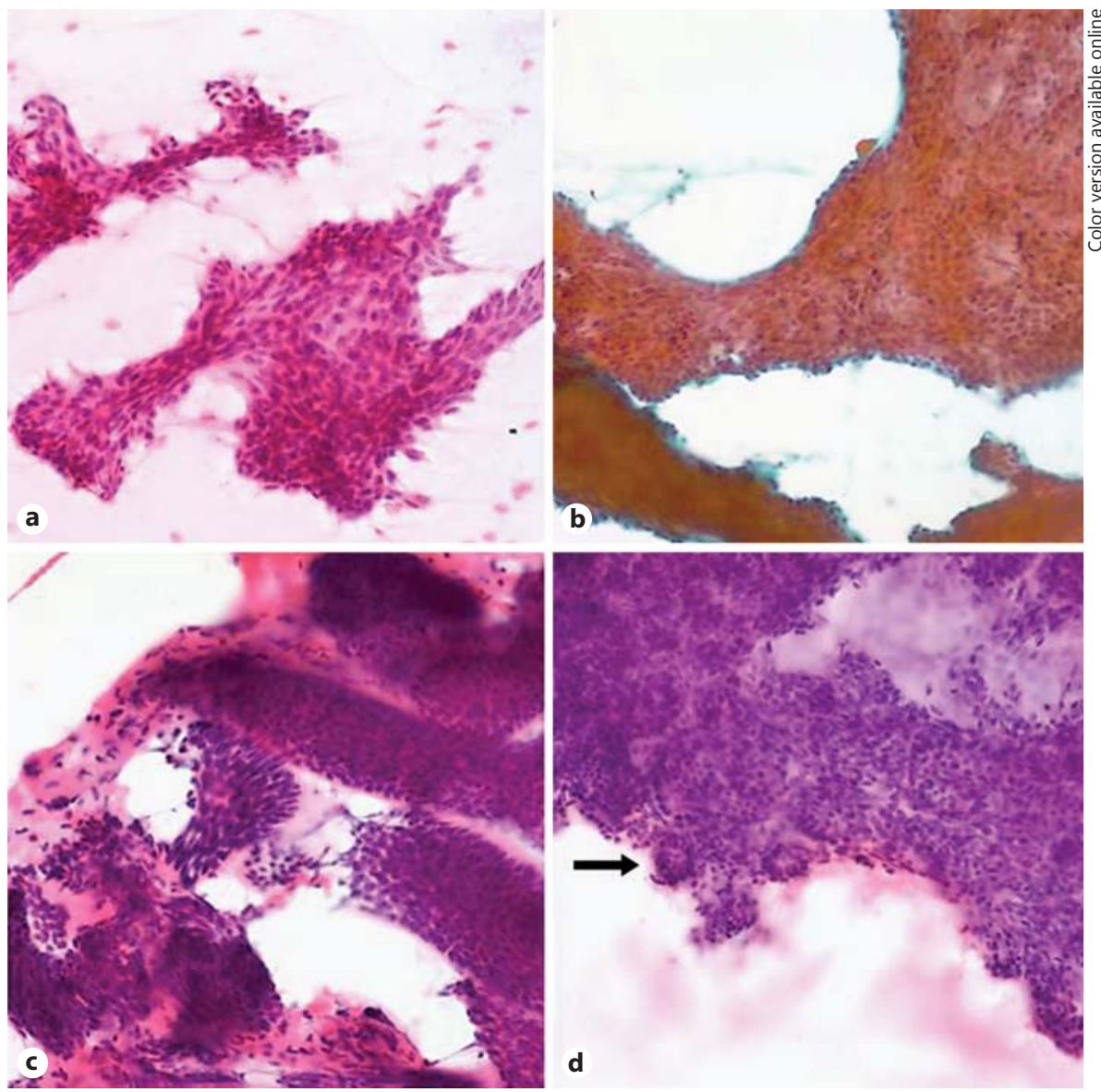

Table 3. Cytologic features of myoepithelioma

\begin{tabular}{ll}
\hline & Cases \\
\hline Arrangement & \\
$\quad$ Cluster + single cells & $4 / 10(40)$ \\
Cluster only & $6 / 10(60)$ \\
Cell type & \\
Spindle & $6 / 10(60)$ \\
Plasmacytoid & $3 / 10(30)$ \\
Epithelioid & $0 / 10(0)$ \\
Clear & $1 / 10(10)$ \\
Stroma & \\
Scant & \\
Fibrillar & $4 / 10(40)$ \\
Hyaline & $3 / 10(30)$ \\
Myxoid & $3 / 10(30)$ \\
\hline
\end{tabular}

Figures in parentheses are percentages.

\section{Cytologic Features of Myoepithelioma}

A total of 11 cytologic slides of myoepithelioma were available and were reviewed by 2 pathologists (table 3 ). Among them, 1 specimen was an inadequate specimen showing cystic fluid with scant cellularity. The rest of the specimens were histologically analyzed.

Myoepithelial cells presented in either loosely cohesive, haphazardly arranged clusters or as single cells. While 4 out of 10 cases were arranged in a cohesive pattern with dispersed single cells (fig. 2a), 6 out of 10 cases were arranged only in cellular clusters (fig. 2b). There were no ductal elements in cytology specimens. The amount of stroma was scant in 4 out of 10 cases. The remainder of cases revealed some stroma, although the amount of stroma was small and could have been easily missed. A palestaining fibrillar matrix and hyaline stroma were found in each of the 3 cases. In contrast to the hyaline stroma lining the periphery of the tumor in basal cell adenomas, the hyaline material was admixed with tumor cells (fig. 2c). There was no chondroid matrix material, which is charac- 
Fig. 2. Cytologic features of myoepithelioma. a Tumor cells are arranged in a cohesive pattern with dispersed single cells. b The smooth borders of the tumor cells mimic basal cell adenoma. c Hyaline material is admixed with tumor cells. d There are occasional intranuclear inclusions.
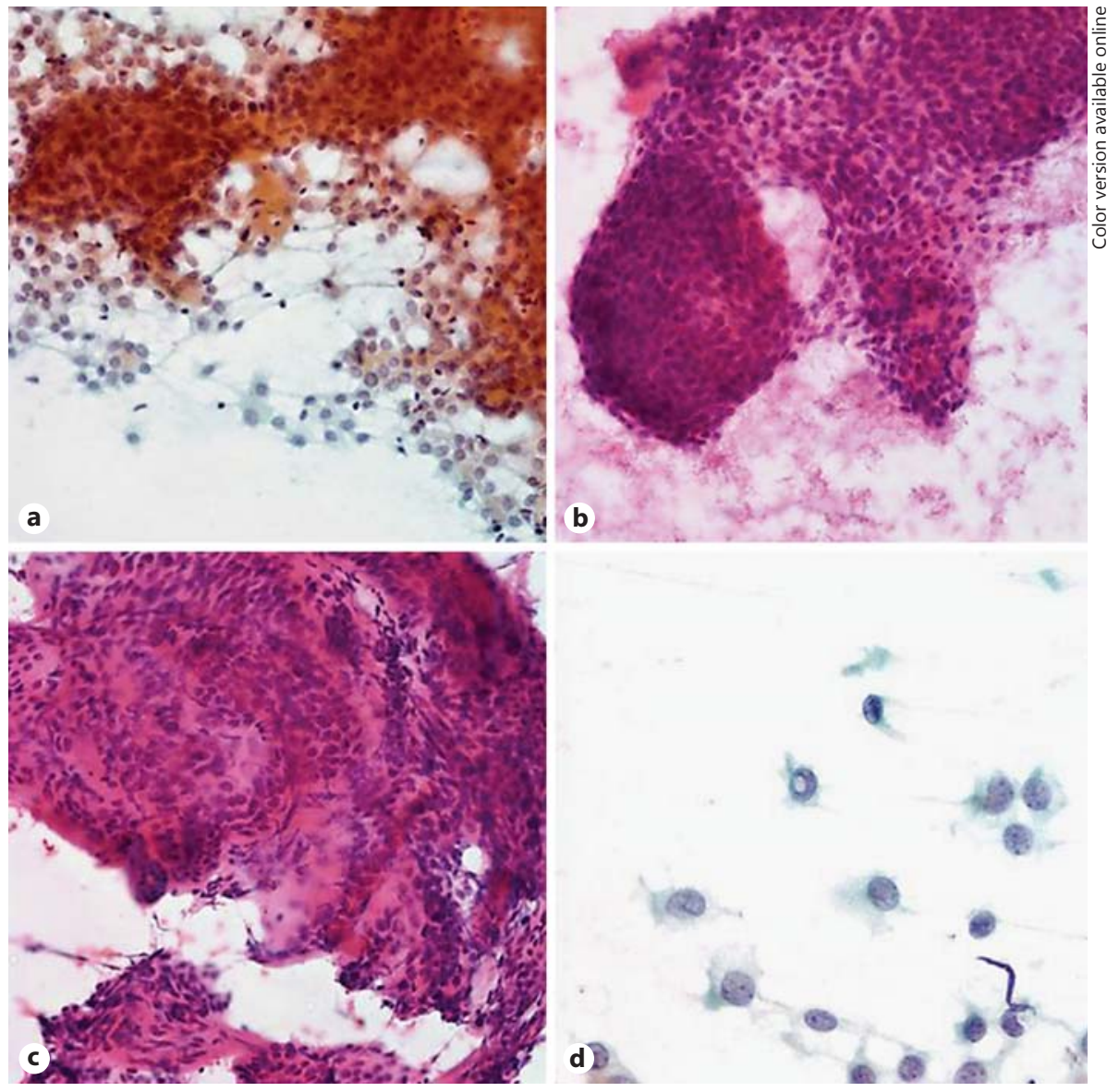

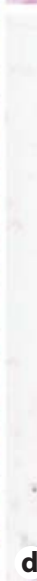

teristic of pleomorphic adenoma. The tumor cells were spindle $(6 / 10)$, plasmacytoid $(3 / 10)$ and clear $(1 / 10)$ cells.

With regard to cytologic atypia, myoepithelial cells were mostly uniform and bland with indistinct nucleoli. The cytoplasm varied from scant cytoplasm to plasmacytoid with dense cytoplasm. In the plasmacytoid type, tumor cells had vesicular nuclei, and 2 of these cases revealed frequent intranuclear inclusions (fig. 2d). Neither necrosis nor mitoses were identified in any reviewed slides. One case of hypercellular smear admixed with hyaline globules was misdiagnosed as adenoid cystic carcinoma (fig. 3). Hyaline globules were admixed with cells and had vaguely feathery outlines and a fibrillar texture.

\section{Discussion}

In this study, we evaluated the diagnostic accuracy of FNA for 3 types of salivary gland tumors with myoepithelial participation, namely, pleomorphic adenoma, myoep- ithelioma and basal cell adenoma. In our study, FNA was found to have a high diagnostic accuracy for these 3 benign salivary gland tumors with myoepithelial differentiation. Although myoepithelioma and basal cell adenoma were rarely given straightforward diagnoses, unlike pleomorphic adenoma, triage into this category provides sufficient information for clinicians to make treatment decisions. In addition, the treatment of these 3 tumors does not differ, as long as they are recognized as benign tumors within this spectrum [7]. We concluded that FNA is an optimal diagnostic tool for the diagnosis of benign salivary tumors, including myoepithelioma and basal cell adenoma. While the distinction between these 3 tumors was difficult to make in many cases due to overlapping features, this had no significant impact on the clinical implications.

There have only been a few studies of the cytologic features and diagnostic accuracy for myoepithelioma and basal cell adenoma [8-17]. With regard to tumor classification, pleomorphic adenoma, myoepithelioma and basal cell adenoma have recently been viewed as neoplasms 
Fig. 3. Histologic and cytologic features of the myoepithelioma case misdiagnosed as adenoid cystic carcinoma.
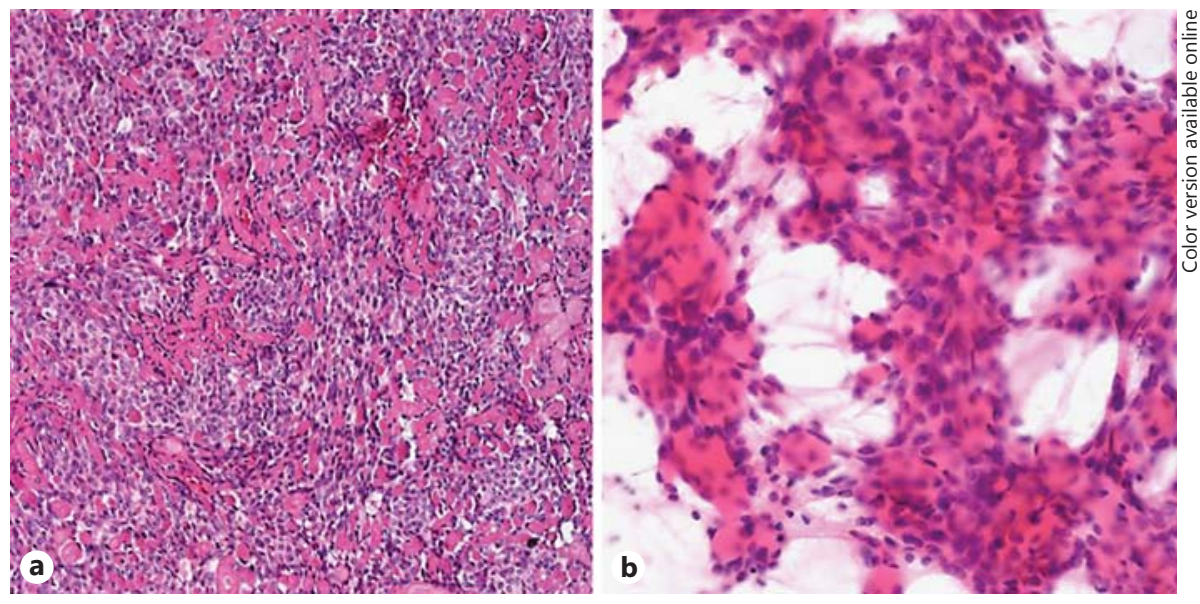

on a spectrum separable by the dominance of the participating cell types. It is well known that myoepithelioma consists exclusively of myoepithelial cells and that pleomorphic adenomas are composed of a mixture of ductal epithelial, basal and myoepithelial cells. However, the histology of basal cell adenoma is more complex. Histologically, basal cell adenoma is a benign tumor composed of basaloid epithelial cells sharply delineated from the stroma by basement membrane-like material and distributed in solid, trabecular, tubular, and membranous patterns [18]. The solid type is composed of sheets or islands of variable shapes and sizes, usually with peripheral palisading of cuboidal to columnar cells. The trabecular type is characterized by narrow strands, trabeculae or cords of basaloid cells separated by cellular and vascular stroma. Ductal lumina are often observed among basaloid cells, and these cases are considered to be the tubule-trabecular type. The membranous type has thick bands of hyaline material at the periphery of the basaloid cells and intercellular coalescing droplets. However, tumors may present with more than one of these patterns. Recently, it was acknowledged that basal cell adenomas also display some degree of myoepithelial cell participation [7]. The participation of morphologically diverse myoepithelial cells (epithelioid, clear, spindle, plasmacytoid) could contribute to the diverse cytologic morphology of basal cell adenoma.

Cytologically, basaloid tumors of the salivary gland are among the most diagnostically challenging areas of salivary glands. The cytologic diagnosis of basal cell adenoma rests on identifying two populations of basaloid cells: a group of small oval cells with bland hyperchromatic nuclei, scant cytoplasm and indistinct nucleoli, and a group of larger oval to polygonal cells with moderate amounts of delicate cytoplasms [18]. Several previous studies have also emphasized the homogeneous appearance of basal cells, the presence of peripheral palisading and the peculiar arrangement of stroma and cells within clusters $[9,11$, $12]$. However, in our experience, only two cell populations are readily identified in tubular or trabecular types of basal cell adenoma. Vicandi et al. [9] were also unable to identify specific cytological features of basal cell adenoma subtypes. In addition, we found that tumor cells often exhibited oval to spindle morphology, which makes their classification as basal cell adenoma difficult. These cells could be regarded as myoepithelial cells with spindled morphologic structures. We acknowledge that possible spindle cell morphology in cytologic slides of basal cell adenoma is noteworthy and that it should be emphasized that basal cell adenomas may sometimes exhibit spindle cell morphology.

Myoepitheliomas are benign tumors composed exclusively, or almost exclusively, of neoplastic cells exhibiting myoepithelial differentiation. In a previous study, the predominant cell morphology in benign myoepithelioma was reported to be plasmacytoid cells, followed by spindle and clear cell populations [10]. Myoepitheliomas lack chondroid matrix material, which is a characteristic feature of pleomorphic adenoma. However, it may be impossible to diagnose myoepithelioma directly because exclusive myoepithelial components may not only be seen in myoepithelioma, but also in pleomorphic adenoma [19]. These tumor cells are commonly arranged in cellular aggregates with scattered single cells. Interestingly, it was often difficult to distinguish these tumors from basal cell adenoma, especially when presented as cellular aggregates with smooth borders. 
In this study, there were 4 false-positive malignancy diagnoses for pleomorphic adenoma, 1 for basal cell adenoma and 2 for myoepithelioma. Among cases of category 2 , the possibility of malignancy was raised in $4.5 \%$ (24/534) of pleomorphic adenomas, $11.5 \%(3 / 26)$ of basal cell adenomas and 6.7\% (1/15) of myoepitheliomas. In practice, deciding whether a tumor is benign or malignant can be a critical clinical issue, as the approach and method of surgery differ according to the diagnosis. Sometimes it is impossible to distinguish benign neoplasms from malignancies because some malignant tumors lack cytologic atypia. In these cases, the presence of invasion is the only criteria to define malignancy. Certainly, basal cell adenomas can never be distinguished on FNA from basal cell adenocarcinomas. In our institution, 1 out of 2 basal cell adenocarcinomas was given a falsenegative diagnosis of basal cell adenoma on preoperative FNA slides. Another challenging problem is the differential diagnosis with adenoid cystic carcinoma, which was the most common false-positive diagnosis in this study. Also, adenoid cystic carcinoma was mentioned as one of the differential diagnoses in many cases of category 3 . This may be primarily due to the basaloid features of adenoid cystic carcinoma. Some cases of cellular pleomorphic adenoma cannot be distinguished from solid adenoid cystic carcinoma and vice versa. In particular, cylindromatous presentation of pleomorphic adenoma can cause diagnostic difficulty [20]. On the other hand, it is also important for pathologists to be aware of the possible presence of mild atypia in these 3 tumors, and caution is warranted to avoid making a false-positive diagnosis. In difficult cases, a definitive diagnosis may need to be deferred until surgical specimen evaluation [6].

There are not only false-positive diagnoses but also many false-negative diagnoses, especially in the case of adenoid cystic carcinoma. In our institution, there were $17.8 \%$ ( 8 out of 45 ) of false-negative diagnoses in FNA slides of adenoid cystic carcinoma and all false-negative diagnoses were pleomorphic adenomas. In addition to overlapping morphology between these two tumors, hyaline globules of stromal material can be seen in both tumors, which makes a differential diagnosis more challenging [21]. The hyaline material in adenoid cystic carcinoma is more homogeneous than that in pleomorphic adenoma $[18,21]$. In adenoid cystic carcinomas, the hyaline material is well defined, homogeneous and acellular $[18,21]$. They lack the embedded myoepithelial cells of pleomorphic adenomas $[18,21]$. The hyaline material in adenoid cystic carcinomas may take various shapes such as balls, branching or finger-like structures, while in pleomorphic adenomas, they mainly form globules $[18,21]$. In pleomorphic adenoma, it has a fibrillar matrix with frayed edges and embedded cells [21]. The nature of the matrix material can be helpful for the distinction of these 2 tumors in addition to cell morphology and atypia [18]. Although these tips are helpful for differential diagnosis, it is still difficult to give a straightforward diagnosis in some cases [21]. Smear artifacts can also result in the matrix of adenoid cystic carcinoma having a focal fibrillary appearance, reminiscent of pleomorphic adenoma [18]. Rarely, pleomorphic adenoma can have a focal adenoid cystic-type matrix [18]. Caution should be warranted in the interpretation of these cases and a descriptive diagnosis should be provided.

In conclusion, our study illustrates that FNA is an accurate and reliable tool for the evaluation of benign salivary gland tumors with myoepithelial participation. Although descriptive signout instead of definite diagnosis was rendered in most cases of myoepithelioma and basal cell adenoma, these cases were successfully triaged to this tumor category. The cytopathologist's knowledge of the basaloid salivary gland tumors with myoepithelial cell participation can prevent both false-positive and falsenegative diagnosis.

\section{References}

1 Viguer JM, Vicandi B, Jimenez-Heffernan JA, Lopez-Ferrer P, Limeres MA: Fine needle aspiration cytology of pleomorphic adenoma. An analysis of 212 cases. Acta Cytol 1997;41: 786-794.

2 Kechagias N, Ntomouchtsis A, Valeri R, Patrikidou A, Kitikidou K, Xirou P, Destouni C, Vahtsevanos K, Antoniades K: Fine-needle aspiration cytology of salivary gland tumours: a 10-year retrospective analysis. Oral Maxillofac Surg 2012;16:35-40.
-3 Riley N, Allison R, Stevenson S: Fine-needle aspiration cytology in parotid masses: our experience in Canterbury, New Zealand. ANZ J Surg 2005;75:144-146.

-4 Stewart CJ, MacKenzie K, McGarry GW, Mowat A: Fine-needle aspiration cytology of salivary gland: a review of 341 cases. Diagn Cytopathol 2000;22:139-146.
5 Eveson JW, Kusafuka K, Stenman G, Nagao $\mathrm{T}$, et al: Pleomorphic adenoma; in Barnes L, Eveson JW, Reichart P, Sidransky D: World Health Organization Classification of Tumors. Pathology and Genetics of Head and Neck Tumours. Lyon, IRAC, 2004, p 254.

-6 Mukunyadzi P: Review of fine-needle aspiration cytology of salivary gland neoplasms, with emphasis on differential diagnosis. Am J Clin Pathol 2002;118(suppl):S100-S115. 
7 Zarbo RJ, Prasad AR, Regezi JA, Gown AM, Savera AT: Salivary gland basal cell and canalicular adenomas: immunohistochemical demonstration of myoepithelial cell participation and morphogenetic considerations. Arch Pathol Lab Med 2000;124:401-405.

>8 Siddaraju N, Badhe BA, Goneppanavar M, Mishra MM: Preoperative fine needle aspiration cytologic diagnosis of spindle cell myoepithelioma of the parotid gland: a case report. Acta Cytol 2008;52:495-499.

$>9$ Vicandi B, Jimenez-Heffernan JA, Lopez-Ferrer P, Gonzalez-Peramato P, Patron M, Viguer JM: Fine needle aspiration cytology of basal cell adenoma of the salivary gland: a cytohistological correlation study of 35 cases. Cytopathology 2012;23:315-319.

10 Khademi B, Kazemi T, Bayat A, Bahranifard H, Daneshbod Y, Mohammadianpanah M: Salivary gland myoepithelial neoplasms: a clinical and cytopathologic study of 15 cases and review of the literature. Acta Cytol 2010; 54:1111-1117.
Hara H, Oyama T, Saku T: Fine needle aspiration cytology of basal cell adenoma of the salivary gland. Acta Cytol 2007;51:685-691.

-12 Kawahara A, Harada H, Akiba J, Yokoyama T, Kage M: Fine-needle aspiration cytology of basal cell adenoma of the parotid gland: characteristic cytological features and diagnostic pitfalls. Diagn Cytopathol 2007;35:85-90.

13 Hruban RH, Erozan YS, Zinreich SJ, Kashima HK: Fine-needle aspiration cytology of monomorphic adenomas. Am J Clin Pathol 1988; 90:46-51.

14 Hood IC, Qizilbash AH, Salama SS, Alexopoulou I: Basal-cell adenoma of parotid. Difficulty of differentiation from adenoid cystic carcinoma on aspiration biopsy. Acta Cytol 1983;27:515-520.

15 Cuadra Zelaya F, Quezada Rivera D, Tapia Vazquez JL, Paez Valencia C, Gaitan Cepeda LA: Plasmacytoid myoepithelioma of the palate. Report of one case and review of the literature. Med Oral Patol Oral Cir Bucal 2007; 12:E552-E555.
6 Kumar PV, Sobhani SA, Monabati A, Hashemi SB, Eghtadari F, Hamidi SA: Myoepithelioma of the salivary glands. Fine needle aspiration biopsy findings. Acta Cytol 2004;48:302-308.

17 Kim NR CH, Ha SY: Cytology of plasmacytoid type myoepithelioma: report of two cases. Korean J Pathol 2009;43:489-493.

18 Faquin WC PC: Salivary Gland Cytopathology. New York, Springer, 2008, pp 97-103, 118-120.

19 Pusztaszeri M, Braunschweig R, Mihaescu A: Pleomorphic adenoma with predominant plasmocytoid myoepithelial cells: a diagnostic pitfall in aspiration cytology. Case report and review of the literature. Diagn Cytopathol 2009;37:56-60.

20 Handa U, Dhingra N, Chopra R, Mohan H: Pleomorphic adenoma: cytologic variations and potential diagnostic pitfalls. Diagn Cytopathol 2009;37:11-15.

21 DeMay RM: The Art and Science of Cytopathology. Chicago, American Society for Clinical Pathology Press, 2012, pp 802-803. 